

Volume 14

Issue 1. Physical Activity and Cultural Safety

Article 4

DOI 10.32799/ijih.v14i1.30861

May 2019

\title{
Cultural Safety Training for Health Professionals Working with Indigenous Populations in Montreal, Quebec
}

Sean Yaphe MD, MPH

St. George's University School of Medicine, Montreal Urban Aboriginal Health Centre sean.yaphe@mail.mcgill.ca

Faisca Richer, M.D., M.Sc., CMSQ, FRCPC

McGill University Department of Biostatistics, Epidemiology, and Occupational Heath faisca.richer@inspq.qc.ca

Carrie Martin, BSc, MSW

Canadian Aboriginal AIDS Network, Montreal Urban Aboriginal Health Centre carriem@,caan.ca

Follow the International Journal of Indigenous Health at:

https://jps.library.utoronto.ca/index.php/ijih/index

\section{Recommended Citation}

Yaphe, S., Richer, F., Martin, C. (2019). Cultural Safety Training for Health Professionals Working with Indigenous Populations in Montreal, Quebec. knowing. IJIH,14(1),60- 84. DOI 10.32799/ijih.v14i1.30861. 


\title{
Cultural Safety Training for Health Professionals Working with Indigenous Populations in Montreal, Quebec
}

\begin{abstract}
Urban Indigenous populations face some of the most significant barriers to accessing health services out of any population in Canada. The Indigenous community in Montreal developed a cultural safety training program to help decrease some of these barriers. An extensive review of published literature on cultural safety in health care was performed. A training program was developed to: describe the diversity of Indigenous populations in Montreal; explain historic and present-day determinants of health inequities in this population; develop competencies to respect clients' diversity and promote cultural safety in care. A pre-test survey was circulated to participants receiving the training to establish baseline knowledge and attitudes towards Indigenous populations. The program was divided into 3 half-day sessions. After each session, a satisfaction evaluation grid survey was circulated to participants. The Indigenous Cultural Safety Training Program was presented to a total of 45 nurses, social workers, and physicians with frequent interactions with the Indigenous community in Montreal. Having an Elder and community member present appeared to have been successful in increasing participants' level of awareness of the importance of improving the quality of health care services provided. Challenges were identified regarding the transmission of the political aspect of the cultural safety concept, and the importance of decolonizing health care systems. Reflections on how to address these in the future will be discussed. Cultural safety training for health professionals is challenging, yet, a necessity to improve access to care and improve health outcomes in urban Indigenous populations.
\end{abstract}

\section{Keywords:}

Cultural safety, Barriers, Health access

\section{Acknowledgements}

We would like to acknowledge Pascale Annoual and Jeffrey Drugge for their involvement in the literature review and organizing the preparation of this training program. In addition, we thank Isabelle Duguay for participating in the extensive literature review.

\section{Creative Commons Licence}

\section{(c) 1 (1) (3)}

This work is licensed under a Creative Commons Attribution-Noncommercial-No Derivative Works 4.0 License. 


\section{Introduction}

The term cultural safety can best be described as "an environment that is spiritually, socially, and emotionally safe, as well as physically safe for people; where there is no assault, challenge or denial of their identity, of who they are and what they need. It is about shared respect, shared meaning, shared knowledge and experience of learning together" (Williams, 1999, p 213). The concept originated in the 1980s in New Zealand as a means to provide more appropriate health services for Maori people (Nursing Council of New Zealand, 2011). It is a combination of cultural awareness (acknowledging the differences between cultures), cultural sensitivity (respect towards other cultures), and cultural competency (effective work with diverse populations through appropriate behaviours, attitudes, and policies (Brascoupé \& Waters, 2009; Darroch et al., 2017). The term made its way into Canadian literature in the early 2000s via the National Aboriginal Health Organization and the Aboriginal Nurses Association of Canada (Schill \& Caxaj, 2019). In recent years, cultural safety has become prominent in health care education and services in Canada, particularly when working with Indigenous populations.

Like elsewhere around the world, Indigenous peoples in Canada face some of the most severe health inequities in comparison to their non-Indigenous counterparts. In addition, the increasing mobility of Indigenous populations from communities towards urban centres in the hopes of improving their living conditions has contributed to making urban Indigenous populations the fastest growing population in Canada. For example, between 2001 and 2011, the Indigenous population living in Montreal grew by 135\% (Aboriginal Affairs and Northern Development Canada, 2014; Government of Canada, 2013). In spite of these populations being in urban centers - where health services are available, and, in principle, "universally accessible" - urban Indigenous people continue to face substantial challenges in terms of access and quality of health and social services in Canada (Allan \& Smylie, 2015); a situation that has resulted in the Indigenous population's lack of trust in the health care systems, hence exacerbating the health iniquities they are currently facing (Montreal Urban Aboriginal Health Committee, 2012).

In 2012, the Montreal Urban Aboriginal Health Committee conducted a Needs Assessment through a series of group and individual interviews with 89 urban Indigenous people (First Nations, Métis, and Inuit) and 94 health service providers (Montreal Urban Aboriginal Health Committee, 2012). The results of this needs assessment revealed that a majority of Indigenous respondents rated their health as poor, and more than half of them reported being dissatisfied with the health services available and provided to them in the city. Reported barriers to care included inadequate levels of cultural safety, discrimination, language barriers, limited access to mental health services, lack of provincial medicare (RAMQ) coverage, lack of identification papers, and prohibitive costs associated with care. In addition, lack of access to traditional healing services and the need for a centrally located, culturally safe, holistic health centre were identified. These barriers were also corroborated by many of the health care providers interviewed. 
Whether patients are First Nations, Métis, or Inuit, it is evident that current services in Montreal are not culturally safe, and do not answer the needs of the population.

British Columbia, Saskatchewan, Manitoba, and Ontario have developed their own cultural safety training programs for health professionals. In British Columbia, the program, known as San'yas, is an online training program that has gained recognition across Canada. Course materials are interactive and investigate culture, stereotyping, and the health and social impacts of colonization. Both Manitoba, and Ontario have adapted the San'yas program to reflect the realities in their respective provinces (Provincial Health Services Authority in BC, 2018; Southwest Ontario Aboriginal Health Access Centre, 2014; Winnipeg Regional Health Authority, 2017). The Saskatoon Health Region has developed an online toolkit for cultural competency and cultural safety that consists of documents encouraging health professionals to engage in reflection, relationship building, and reconciliation (Saskatoon Health Region, 2016). Finally, the National Indigenous Cultural Safety Learning Series is a partnership between the Provincial Health Services Authority of British Columbia and the Southwest Ontario Aboriginal Health Access Centre that provides monthly webinars of 90 minutes in duration (Indigenous Cultural Safety Collaborative Learning Series, 2019). The goal is to bring together key provincial, federal, and international stakeholders in order to collaborate and provide a shared learning environment for cultural safety.

In New Zealand, cultural safety teaching has been an integral part of nursing education since the 1990s. Cultural safety teachers informed nursing students of the positive impact of attitude changes on the delivery of health services, and, examined the power imbalances often seen in the nurse-patient relationship. The New Zealand Education Department hired a Maori Education Officer to introduce bicultural education into the nursing curriculum. This new curriculum was developed through partnerships between the New Zealand Council of Maori Nurses, the Department of Education, Department of Health, and Maori and Pakeha (Maori term for New Zealanders of European descent) nurse educators. This partnership addressed the needs of nursing students and the needs of Maori. Since its inclusion almost 30 years ago, the debate about how cultural safety should be incorporated into nursing education continues; however, it is evident that the facilitated group process is the best model for students to learn, and develop discourse in a supportive environment (Richardson \& Carryer, 2005).

In Australia, the National Aboriginal and Torres Strait Islander Health Workers Association (NATSIHWA) launched their cultural safety framework in 2013. This framework focuses on 8 critical domains: country and community; local cultural contextuality; recognizing and valuing the role of Aboriginal and Torres Strait Islander health workers; individual reflection; systemic reflection; equity and sustainability; collaboration and cooperation; and monitoring and evaluation (National Aboriginal and Torres Strait Islander Health Workers Association, 2013). 
It is evident that Quebec has much work to do to ensure culturally safe, accessible health services for Indigenous people. In addition to the lack of cultural safety training for health professionals, Indigenous people in Quebec's urban settings lack appropriate centres for health care. In Ontario, for example, 10 Aboriginal Health Access Centres (AHAC) provide culturally safe care to Indigenous communities, as well as comprehensive cultural safety training to their health care professionals (Southwest Ontario Aboriginal Health Access Centre, 2014). The Wabano Centre for Aboriginal Health in Ottawa, Ontario is a successful example, providing a multitude of services to promote the health of all Indigenous People in a culturally safe environment (Wabano Centre for Aboriginal Health, 2017). In Toronto, Ontario, Anishnawbe Health Toronto was created in 1984 and services the community in 3 locations across the Greater Toronto Area. These services include primary care, diabetes prevention, education, and management, family services, mental health and addiction services, and fetal alcohol spectrum disorder services following a traditional model of care that includes Traditional Healers, Elders, and Medicine People (Anishnawbe Health Toronto, 2013).

The structure of the health care system in Quebec presents challenges in terms of implementing cultural safety training and developing a culturally safe, holistic health centre for Indigenous people. Currently, primary care services are housed under one roof in local health service centres, with the emphasis on inclusion and access for all. In reality, this causes disjointed service provision. Some of the issues that exist for the general population include minimal walk-in hours, long wait times, and often minimal staffing to support the needs of the area it serves (Loopie Reading \& Wien, 2009). In combination with the aforementioned barriers to access to health services described in the Health Needs Assessment, significant structural and individual problems must be addressed to ensure equitable access to health services in a culturally safe environment.

Additionally, from a medical education standpoint, it is only within the last few years that schools in Canada have begun implementing Indigenous curricula as part of the core training for future physicians. In Quebec, the idea of Indigenous teaching in health education is still in development. Most of the health care workers who are already in practice have had limited exposure to these issues as part of their professional training. Moreover, although there has been an increased focus on Indigenous health in Canadian health education curricula in recent years, it appears that cultural competency has been the area of focus thus far in nursing and medicine programs, which, as explained earlier, falls short of truly bringing equity in care for Indigenous peoples (Verma, 2017).

With the rapid urbanisation of Indigenous populations in the province, health care professionals working in urban centers are sure to see an increasing number of Indigenous patients, whether they practice in Emergency Departments, primary health care clinics, or in hospitals. 
It is with this context in mind that the Montreal Urban Aboriginal Health Centre, in conjunction with the Institut National de Santé Publique du Québec, developed and piloted training material aimed at health care professionals already in practice in the city. The main goal of this training was to develop the professionals' knowledge, abilities, and attitudes to better understand and address barriers to care for Indigenous peoples in Montreal.

\section{Methods}

This project was a partnership between the Montreal Urban Aboriginal Community Strategy Network's (NETWORK) health working committee and the Institut National de Santé Publique du Québec (INSPQ). The NETWORK is an organisation that was created in 2008 to improve the quality of life of the Aboriginal people in the greater Montreal area through a coordinated and concerted approach. The NETWORK encompasses six working groups: health, arts and culture, social services, youth, employability and education, and communications. The health working committee recently incorporated one of its sub-committees in order to secure funding and grant opportunities to develop a culturally safe holistic health centre for the urban Indigenous population in Montreal - the Montreal Urban Aboriginal Health Centre.

The INSPQ was created in 1998 as the centre for expertise in public health in Quebec. The Indigenous Health team of the INSPQ was created in 2008, with the objective of supporting Indigenous organisations in developing and implementing strategies to improve the health and well-being of the Indigenous populations in the province.

\section{Training material development and piloting}

Beginning in the summer of 2016, members from the INSPQ working team conducted an exhaustive review of the published literature, documenting the components and efficiency of already existing cultural safety training programs that were developed elsewhere in Canada and across the globe. From this documentation, a training manual was drafted and validated by members of the NETWORK's health working committee. While many programs developed across Canada were implemented via online training sessions, in discussions with health professionals in Montreal, it was felt that in-person sessions would be more valuable as health professionals are constantly bombarded with required online training sessions. It was thought that to continue with this format would not place sufficient emphasis on the importance of cultural safety training. Additionally, in-person interaction with Elders and Indigenous community members, and hearing their stories first-hand, would provide greater impact and a stronger message to alter subsequent health services. 
In the summer of 2017, the team was approached by one of the Integrated Primary Care Centers of Montreal with a request to provide training to some of their interdisciplinary health care teams working with marginalised populations in the city. The group of health care professionals was divided into two subgroups of 20-25 participants each, and each received three sessions of three hours each. Sessions began with a ceremony and opening prayer by an Elder. The goal of the training was to develop participants' ability to:

(1) Recognize the sociocultural and socioeconomic diversity of Indigenous populations in Montreal;

(2) Describe the links between the history of colonisation in Canada and the current health status of the Indigenous population; and

(3) Apply a cultural safety approach when interacting with Indigenous patients, by developing their ability for reflective practice, cultural humility, and respect.

Training facilitators included an Elder, a First Nation's community member, as well as a non-Indigenous public health physician and a medical student with clinical experience in Indigenous populations.

The project submitted did not require REB review because it aimed to assess the performance of a training activity, as part of regular quality assurance and quality improvement activities as stipulated in article 2.5 of the Tri-Council Policy Statement: Ethical Conduct for Research Involving Humans.

\section{Training evaluation}

A process evaluation of this pilot training was conducted in order to evaluate the satisfaction of participants with the training, as well as to test the feasibility of incorporating the training program in primary care centres in Montreal. To achieve this, a questionnaire was provided to all participants prior to the first training session; this pre-training needs assessment was meant to develop an appreciation of participants' level of knowledge on issues surrounding Indigenous peoples and cultural safety. In addition, a satisfaction assessment grid was provided after each training session, where participants could rate their experience of the session and provide comments on how it could be improved.

\section{Results}

A total of 45 health care professionals (including nurses, social workers, and physicians) were initially enrolled in the nine-hour training. The training sessions were held between December 6, 2017 
and March 20, 2018. The questionnaires that were distributed to participants at each session can be found in the appendices.

Table 1 below presents the results of the initial needs assessment. About a third of participants reported having already received some form of Indigenous health training. While participants appeared to already be quite knowledgeable in the realities and challenges faced by Indigenous peoples accessing health services in Montreal, the vast majority of them admitted being unaware of the concept of cultural safety. An average score of five (5) good answers out of 10 questions was achieved on the knowledge scale, with the highest score $(9 / 10)$ being achieved only by a very small minority of participants. The questions that were most often missed were the ones pertaining to the rapid growth rate and language barriers faced by the Indigenous population in Montreal.

Table 1: Pre-training needs assessment results

\begin{tabular}{|l|l|l|}
\hline & Average & Maximum \\
\hline $\begin{array}{l}\text { Knowledge of Indigenous } \\
\text { Peoples in Canada }\end{array}$ & $5 / 10$ & $9 / 10$ \\
\hline $\begin{array}{l}\text { Beliefs and attitudes with regards } \\
\text { to the care of Indigenous Peoples } \\
\text { in Montreal. }\end{array}$ & $6 / 7$ & $7 / 7$ \\
\hline
\end{tabular}

Moreover, the vast majority of participants seemed to demonstrate a positive attitude towards Indigenous patients in general, acknowledging that this population continues to face discrimination within the health system. The overall average on the 'attitudes' scale was of six (6) good answers out of seven (7) questions, with approximately one third (1/3) of participants receiving a perfect (seven (7) out of seven (7)) score.

When asked to define the term "cultural safety", the vast majority of participants came up with a definition that appeared to be closer to that of "cultural competency" than of "cultural safety". Yet, approximately one third of participants (28\%) did define cultural safety as a way of providing care that is "adapted to the needs of the patient". Also, a small number of participants admitted that providing a culturally safe environment was difficult in the current health care context, mostly due to structural and organisational constraints, particularly when referring patients to other institutions than their own.

When asked about training expectations, almost half of participants noted that they wanted to "learn more about the culture, values, and beliefs of Indigenous people" (again reflecting more of an interest in cultural competency than cultural safety itself). In addition, a quarter of the participants chose 
not to answer this question, which may have indicated a lack of interest in (or a perception of lack of pertinence of) the training itself. Yet, the remaining quarter of participants provided answers that revolved around cultural safety principles, such as "interest in knowing how to remove barriers to adequate interventions", as well as "learning more on the needs and desires of the Indigenous population in terms of health and health care services".

As the sessions went on, participation in the post-training satisfaction evaluation dropped from $98 \%$ to $29 \%$, likely indicating a decreased interest in the evaluation over time. On a whole, the evaluation grids received revealed positive reactions to the training program.

Table 2: Session evaluation

\begin{tabular}{|l|c|l|l|}
\hline & Module 1 (N=44) & $\begin{array}{l}\text { Module } \\
(\mathrm{N}=12)\end{array}$ & $\begin{array}{l}\text { Module } \\
(\mathrm{N}=13)\end{array}$ \\
\hline & $\begin{array}{c}\text { \% Satisfied/very } \\
\text { satisfied }\end{array}$ & $\begin{array}{c}\% \text { Satisfied/very } \\
\text { satisfied }\end{array}$ & $\begin{array}{c}\% \text { Satisfied/very } \\
\text { satisfied }\end{array}$ \\
\hline Pertinence of content & $91 \%$ & $83 \%$ & $54 \%$ \\
\hline Pertinence for practice & $73 \%$ & $67 \%$ & $54 \%$ \\
\hline Quality of the trainers & $89 \%$ & $75 \%$ & $92 \%$ \\
\hline
\end{tabular}

The inclusion of an Elder as one of the facilitators appears to have been perceived as a very strong aspect of the training provided, and many participants reported having appreciated the traditional opening ceremony during the first training session. They felt her presence and testimonies made them more aware of Indigenous realities.

"Re-telling of events from the elder were touching and pertinent"

"It made me realise that I have to take into account heritage to better listen to Indigenous People"

Areas for improvement reported by participants included increased discussion time to ask questions to trainers, as well as to share experiences among participants. On the other hand, many declared that offering the training over 3 sessions was too long and that two sessions would have been sufficient to cover the topics presented. A small minority of participants did express their profound dissatisfaction with the "tone" of the training, as they perceived it to constitute a form of judgement towards "white" people. 
"A more neutral tone would have been appreciated as there was some discrimination felt towards health care professionals"

"Events that were described showed judgement towards 'white' people and not all 'white' people have prejudices against Indigenous Peoples"

\section{Discussion}

\section{Lessons learned from our pilot training evaluation}

The present work was aimed at evaluating the satisfaction and feasibility of providing cultural safety training to health care professionals working in the primary care setting in Montreal. We were able to observe that the majority of participants seemed unaware of the concept of cultural safety prior to receiving the training sessions; hence, many were expecting the training to cover topics that are more related to cultural competency than to cultural safety principles. This raises the issue of the weaknesses in health education in Canada when it comes to training professionals on Indigenous health.

Our evaluation results also raised the questions of what would constitute essential factors to ensure the success of future cultural safety trainings in health care institutions in Quebec. Building on existing guidelines for effective change of practice for health care professionals, our experience seems to reiterate the importance of ensuring that the need for trainings be identified by the health care professionals themselves. Indeed, it was felt that the mandatory status of the training we provided could have explained the attrition challenges we faced.

Additionally, the number of participants in such training sessions should be small enough to allow for better interaction. It appeared that having more than 20 individuals per session made it difficult to engage participants in discussions. Yet, participants seemed to have appreciated the opportunity for interdisciplinary conversations, making the interaction between nurses, social workers, and physicians vital during cultural safety training. A portion of the training should bring together participants from the same profession so that they can more easily share past experiences. In order to achieve discussion and to share experiences, other training programs have incorporated a talking circle model.(Jain, Peters, \& Lambright, 2017) This can allow participants to reflect on the mornings content in the presence of an Elder, and perhaps a Traditional Healer as well, to debrief. Additionally, this adds another element of an Indigenous framework to the training program.

Finally, we realised that, for some participants, the content of cultural safety trainings constituted a "tough pill to swallow". Cultural safety training requires covering sensitive topics such as systemic 
racism and structural discrimination, as well as concepts of colonialism and assimilation that were likely never addressed as part of core training. Some seemed to have felt that these discussions constituted an unwelcome critique of their performance as health care workers. We have to admit we were initially surprised with the strength of dissatisfaction being expressed. Upon further reflection, however, it came to light that this sense of discomfort was in fact a necessary first step towards evoking change within the health care system. Disclosing the sensitive and difficult nature of the material prior to the start of training would allow for individuals to be more prepared. The presence of an Elder should also help in creating a dialogue and debriefing participants.

The inclusion of an Elder and Indigenous community members in the facilitation of the training is of utmost importance. The direct interaction with members of the community lowers the resistance towards learning about Indigenous health, knowledge, and cultural safety (Ranzijn, McConnochie, Day, Nolan, \& Wharton, 2008). Furthermore, recent studies have shown that this interaction leads to an increased interest in continuing to engage with the Indigenous community via volunteering and employment (Roche, 2014; Roche, Jones, Hinman, \& Seoldo, 2007).

It is difficult to compare this cultural safety training program to other existing models as few publications exist. San'yas, however, was recently evaluated in the EQUIP Study (Equity Oriented Primary Health) (Masinde, 2017). This study combined staff education with strategies for encouraging the provision of equity-oriented care for marginalized populations in a community. Eighty staff members took the San'yas Indigenous Cultural Safety online training, many of whom were already knowledgeable about cultural safety and anti-discriminatory care. It was noted that the training encouraged staff to challenge institutional discrimination as determinants of poor health and wellness. They also noted an importance on improving patient-physician relationships, as well as the relationships within the community. Participants mentioned that many aspects were difficult to integrate at the clinic level due to structural challenges in the design and flow of a clinic. In addition, tension developed when participants tried to prioritize varying aspects of care that strayed away from a biomedically-influenced health care delivery system. The EQUIP study provided strong evidence for participant self-reflection. Participants were able to evaluate how they presented themselves, how they were perceived by patients, and how this could result in barriers to care.

From this evaluation of the San'yas Indigenous Cultural Safety online training, there are many similarities to our pilot project in Montreal. Participants found it difficult to prioritize other aspects of care and to acknowledge the difference in the patient-physician relationship when working with Indigenous patients. Additionally, there was limited awareness of cultural safety prior to commencing this training. With the advent of cultural safety training built into educational programs, future health professionals 
should be cognisant of the key points of cultural safety and will be better suited to incorporate these into their practice.

Finally, this pilot training stresses the importance of early cultural safety education. Not only is it important that training be incorporated into the structural organization of a workplace but must also be integrated into formal professional and medical training. A recent literature review investigated cultural safety education in post-secondary health sciences curricula in Australia, Canada, New Zealand, and the USA (Kurtz et al., 2018). This review found 40 articles published between 1996 and 2016 that investigated cultural safety education in health science education. Thirteen were interdisciplinary in nature, while 11 studies focused on nursing education, and 6 focused on medicine. Other specialties included dentistry, pharmacology, psychology, social work, audiology, and midwifery. Surprisingly, more than half of the curricula examined did not include Indigenous people in the development or delivery of the training. The programs that developed a university-community partnership found it to be highly mutually beneficial. Programs held consultation between faculty, students, Indigenous community practitioners and community representatives, and this was found to successfully meet the learning needs of students, while also being an asset to the community. In Australia, New Zealand, and the USA, students who received cultural safety education prior to practicum experience were also noted to be more aware of health care power imbalances. This, also, increased their confidence and cultural humility in their practice.

Six studies in this review stemmed from Canada (Kurtz et al., 2018). Arnold, Appleby, and Heaton (2008) assessed a cultural immersion weekend with $4^{\text {th }}$ year nursing students and community members. The nursing students gained a better understanding of Indigenous health inequities and the effects of colonialism. Community members met staff and attended career fairs and saw nursing as a viable career choice. Bernhardt et al. (2011) studied a training program in audiology and speech language pathology. This was an 8-month course developed by an advisory group comprised of Indigenous and non-Indigenous community representatives, academics, practitioners, a project coordinator, and student assistants. The curriculum consisted of face-to-face class meetings, student community visits, as well as a website containing articles, announcements, and a discussion forum. Students found they were better prepared to work with the Indigenous community and had a broader understanding of culture after course completion. Carter and Rukholm (2009) studied an interdisciplinary model consisting of nursing, medicine, social work, and health promotion in collaboration with four universities. An Elder directed the curriculum that contained online learning modules. There was increased personal growth and increased awareness of Indigenous health beliefs/attitudes and inter-professionalism. Hudson and Maar (2014) developed a pilot study for medical and nursing students in collaboration with Northern Ontario's Aboriginal political bodies and organizations. Students had mandatory placement in Indigenous communities for 2 weeks and a 2-week on-campus session with online material. It was found that greater in-class preparation was necessary and there was a lack of meaningful discussion online. Jarvis-Selinger et al. (2008) described a social accountability model collaborating with community health administrators, Indigenous community 
members, health professionals, policy makers, and Indigenous leaders to provide training to medical, pharmacy, nursing, and social work students. This was a 4-week community immersion program taught by Indigenous university and community instructors. They found that there was a greater need to integrate an Indigenous perspective into health curricula, as well as social accountability. Kline, Godolphin, Chhina, and Towle (2013) developed an interdisciplinary health science approach whereby students participated in a summer camp for Indigenous youth led by Elders, youth workers, and cultural leaders. The students developed self-awareness, cultural humility, and respect for Indigenous people and cultures. This review acknowledged that more cultural safety education is necessary in Canada prior to the immersion of medical and nursing students into the field.

\section{Drawing from the behaviour change literature}

As often mentioned in the competency-development literature, the content of such training should address the participants' self-perceived learning needs, but also their initial level of knowledge. Indeed, as observed in our pilot training, when participants present with a wide range of backgrounds and funds of knowledge with regards to Indigenous peoples, it can make achieving common learning objectives difficult. This is why it is important for facilitators to ask participants to complete a pre-training needs evaluation prior to the start of the sessions. This will ensure that trainers can adjust the training content to best fit the needs of each group.

As cultural safety training programs are increasingly being developed and implement, the topic of "white resistance" is emerging. Currently very limited published empirical research exists. Yet, drawing from the behaviour change literature and the challenges to behavioural change in health care institutions, we believe Prochaska's Transtheoretical Model may be useful in adapting training content according to participants' readiness to change (Prochaska \& Velicer, 1997). Prochaska's model is used widely in health care as a method for counselling patients on behavioural change. It states that there are 6 stages people move through when they modify a specific behaviour. The precontemplation stage is the initial stage. Individuals at this stage are uninformed and not ready to take action. At the contemplation stage, individuals become aware of problems with a specific behaviour and are intent on making a change. At the preparation stage, an individual has started taking action, or is getting ready to do so in the immediate future. Individuals in the action stage have made specific, measurable changes. At the maintenance stage, individuals are becoming more confident in the changes they have made and less tempted to relapse. The termination stage represents the final stage where individuals are no longer tempted by previous behaviour. This model has been extremely useful in moving patients along the continuum of smoking cessation, for example. This model has also been used and adapted to organisational change in complex institutions (C. Bareil, 2004; C. Bareil \& Gagnon, 2004). Based on Western conceptions of behavioural 
and organisational change, we believe this is an appropriate model that fits well with the epistemological perspective of the health care providers and service institutions we are attempting to change.

From a cultural safety standpoint, individuals who are in the pre-contemplation stage do not see current practices and systems as creating barriers to care for Indigenous people. These individuals may need to be challenged in their convictions. This can be achieved by reviewing Canadian history of colonisation and colonialist policies through an Indigenous lens that will magnify the consequent health inequities. Participants at this stage, might require a significant amount of "credible evidence" demonstrating the impact of barriers to access to health care on Indigenous people, as well as a number of high quality research findings demonstrating how improved cultural safety can contribute to improving health outcomes in this population.

In contrast, participants who are already aware of the systemic barriers to care that Indigenous people face would be in the contemplation or preparation stage. They may find a review of history and evidence repetitive and may seek real concrete solutions. These participants will benefit from training focusing on developing practical skills and advice on how to become cultural safety champions within their organisations. Furthermore, these individuals are ideally suited to be future cultural safety trainers.

Research on the factors that facilitate health care professionals' change of practice has demonstrated the importance of organisational support in driving and maintaining change. It is essential that health care managers be present during cultural safety trainings. In fact, some even advocate for training health care system managers and decision-makers prior to offering trainings to health care professionals This ensures that the required organisational changes are in place before health care professionals receive training (Satterwhite, Teng, \& Fernandopulle, 2007). In the cultural safety context, one of the most vital structural changes to improve health access is hiring Indigenous staff. Working closely with Indigenous community members will also improve health care professionals' understanding of the needs of the community. Finally, integrating cultural safety into institutional performance evaluations is important in order for both institutions and individuals to be held accountable for this collective change of practice.

\section{Conclusion}

This published evaluation of a pilot cultural safety training was, to our knowledge, the first of its kind in Montreal's health care system and it was found to be an overall positive experience. Going further, many adjustments can be made to improve the success of future trainings, including shortening its length, as well as ensuring that group size and time management allows for sufficient discussions between participants. Additionally, Indigenizing the training format through more inclusion of an Elder, talking 
circles, and the presence of a Traditional Healer could allow for more meaningful discourse and a safer space for both participants and trainers. Success of such trainings also require that facilitators have a good a priori understanding of the baseline knowledge about Indigenous peoples and cultural safety principles, so that groups can be set up to bring together participants with similar learning needs, when it comes to their "readiness" to change practice.

Building on organisational change literature, we can also suggest that health care managers and decision-makers be trained on cultural safety principles before their employees/professionals receive the training, so that institutions' missions and procedures can support professional interventions in providing a health care environment where Indigenous patients can truly feel welcome, respected, and safe at all levels of care. Most importantly, one should not forget that cultural safety training cannot be done without Indigenous facilitators present, so as to be truthful to the basic principle of "never again about us without us".

\section{References}

Aboriginal Affairs and Northern Development Canada. (2014). Urban Aboriginal Peoples. Retrieved from http://www.aadnc-aandc.gc.ca/eng/1100100014265/1369225120949

Allan, B., \& Smylie, J. (2015). First Peoples, second class treatment: The role of racism in the health and well-being of Indigenous peoples in Canada. Retrieved from

Anishnawbe Health Toronto. (2013). Anishnawbe Health Toronto 2013 Client Satisfaction Survey Final Report. Retrieved from Toronto:

Arnold, O., Appleby, L., \& Heaton, L. (2008). Incorporating cultural safety in nursing education. Nurs $B C, 40(2), 14-17$.

Bareil, C. (2004). La résistance au changement: synthèse et critique des écrits. Cahier de recherche (HEC Montréal), 4(10).

Bareil, C., \& Gagnon, J. (2004). Building employees' capacity to adapt to change. Cahier de recherche (HEC Montréal), 4(3).

Bernhardt, B., Green, E., Khurana, A., Laporte, T., Osmond, S., Panchyk, H., . . Campbell, H. (2011). Course development at the University of British Columbia concerning audiology and speechlanguage pathology for people of First Nations, Métis and Inuit heritage. Canadian Journal of Speech and Language Pathology and Audiology, 35, 178-189.

Brascoupé, S., \& Waters, C. (2009). Cultural Safety Exploring the Applicability of the Concept of Cultural Safety to Aboriginal Health and Community Wellness. International Journal of Indigenous Health, 5(2).

Carter, L., \& Rukholm, E. (2009). Partnering with an Aboriginal community for heath and education. Canadian Journal of University Continuing Education, 35, 45-60. 
Darroch, F., Giles, A., Sanderson, P., Brooks-Cleator, L., Schwartz, A., Joseph, D., \& Nosker, R. (2017). The United States Does CAIR About Cultural Safety: Examining Cultural Safety Within Indigenous Health Contexts in Canada and the United States. Journal of transcultural nursing : official journal of the Transcultural Nursing Society, 28(3), 269-277. doi:10.1177/1043659616634170

Government of Canada. (2013). 2011 National Household Survey: Data tables. Retrieved from http:/www12.statcan.gc.ca/nhs-enm/2011/dp-pd/dt-td/Apeng.cfm? $\mathrm{LANG}=\mathrm{E} \& A P A T H=3 \& D E T A I L=0 \& D I M=0 \& \mathrm{FL}=\mathrm{A} \& \mathrm{FREE}=0 \& \mathrm{GC}=0 \& \mathrm{GID}=0 \& \mathrm{GK}$ $=0 \& \mathrm{GRP}=0 \& \mathrm{PID}=105387 \& \mathrm{PRID}=0 \& \mathrm{PTYPE}=105277 \& \mathrm{~S}=0 \& \mathrm{SHOWALL}=0 \& \mathrm{SUB}=0 \& \mathrm{Tempo}$

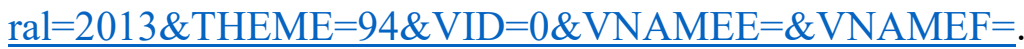

Hudson, G. L., \& Maar, M. (2014). Faculty analysis of distributed medical education in Northern Canadian Aboriginal communities. Rural Remote Health, 14(4), 2664.

Indigenous Cultural Safety Collaborative Learning Series. (2019). The National Indigenous Cultural Safety Collaborative Learning Series. Retrieved from http://www.icscollaborative.com/home

Jain, V., Peters, C., \& Lambright, D. (2017). Pursuing Cultural Safety: From Unearthing Bias to Realizing Reconciliation. Vancouver: First National Health Authority.

Jarvis-Selinger, S., Ho, K., Lauscher, H. N., Liman, Y., Stacy, E., Woollard, R., \& Buote, D. (2008). Social accountability in action: University-community collaboration in the development of an interprofessional Aboriginal health elective. J Interprof Care, 22 Suppl 1, 61-72. doi:10.1080/13561820802052931

Kline, C., Godolphin, E., Chhina, G., \& Towle, A. (2013). Community as teacher model: health profession students learn cultural safety from an Aboriginal community. Michigan Journal of Community Service Learning, 20, 5-17.

Kurtz, D. L. M., Janke, R., Vinek, J., Wells, T., Hutchinson, P., \& Froste, A. (2018). Health Sciences cultural safety education in Australia, Canada, New Zealand, and the United States: a literature review. Int J Med Educ, 9, 271-285. doi:10.5116/ijme.5bc7.21e2

Loopie Reading, C., \& Wien, F. (2009). Health Inequalities and Social Determinants of Aboriginal Peoples' Health. Retrieved from

Masinde, W. M. (2017). A report on the impact of an integrated cultural safety and antidiscrimination training process on staff working in two primary Health Care Centres. (Masters in Nursing), University of British Columbia.

Montreal Urban Aboriginal Health Committee. (2012). Montreal Urban Aboriginal Health Needs Assessment. Retrieved from Montreal:

National Aboriginal and Torres Strait Islander Health Workers Association. (2013). Cultural Safety Framework. Retrieved from Australia:

Nursing Council of New Zealand. (2011). Guideline for Cultural Safety, the Treaty of Waitangi and Maori Health in Nursing Education and Practice. Retrieved from New Zealand: 
Prochaska, J. O., \& Velicer, W. F. (1997). The transtheoretical model of health behavior change. Am J Health Promot, 12(1), 38-48. doi:10.4278/0890-1171-12.1.38

Provincial Health Services Authority in BC. (2018). San'yas Indigenous Cultural Safety Training. Retrieved from http://www.phsa.ca/health-professionals/education-development/sanyasindigenous-cultural-safety-training

Ranzijn, R., McConnochie, K., Day, A., Nolan, W., \& Wharton, M. (2008). Towards cultural competence: Australian Indigenous content in undergraduate psychology. Australian Psychologist, 43(2), 132-139. doi:10.1080/00050060701762554

Richardson, F., \& Carryer, J. (2005). Teaching cultural safety in a New Zealand nursing education program. J Nurs Educ, 44(5), 201-208.

Roche, V. F. (2014). The Sustained, Positive Impact of a Native American Cultures and Health Course on Students' Education and Practice-Related Choices. American journal of pharmaceutical education, 78(9), 172-172. doi:10.5688/ajpe789172

Roche, V. F., Jones, R. M., Hinman, C. E., \& Seoldo, N. (2007). A service-learning elective in Native American culture, health and professional practice. American journal of pharmaceutical education, 71(6), 129-129.

Saskatoon Health Region. (2016). Cultural Competency \& Cultural Safety Toolkit. Retrieved from https://www.saskatoonhealthregion.ca/locations services/Services/HealthObservatory/Documents/ResourceCentre/CCCS\%20Toolkit\%20\%20Reflection\%20Infographic\%20-\%20combined.pdf

Satterwhite, F., Teng, S., \& Fernandopulle, A. (2007). Cultural Competency in Capacity Building. Retrieved from

Schill, K., \& Caxaj, S. (2019). Cultural safety strategies for rural Indigenous palliative care: a scoping review. BMC Palliat Care, 18(1), 21. doi:10.1186/s12904-019-0404-y

Southwest Ontario Aboriginal Health Access Centre. (2014). Ontario Indigenous Cultural Safety Program. Retrieved from http://soahac.on.ca/ics-training/

Verma, S. (2017). Report on Indigenous Health Activities. Retrieved from

Wabano Centre for Aboriginal Health. (2017). Traditional Medicine. Retrieved from http://wabano.com/clinic/traditional-medicine/

Williams, R. (1999). Cultural safety--what does it mean for our work practice? Aust N ZJ Public Health, 23(2), 213-214.

Winnipeg Regional Health Authority. (2017). WRHA Indigenous Health - Cultural Initiatives. Retrieved from http://www.wrha.mb.ca/aboriginalhealth/services/spiritual.php 


\section{Appendix 1: Timeline for the half-day sessions}

Module 1: Comprendre l’origine des iniquités vécues par les populations autochtones au Canada

Ce premier module s'échelonnera sur deux demi-journées, soit les 6 et 19 décembre, pour le groupe 1 et les 8 et 20 décembre pour le groupe 2 .

Première demi-journée (6 et 8 décembre)

Formateurs : Carrie Martin, Aîné, Faisca Richer

9h-10h. Introduction et contexte

Mot de bienvenu et de reconnaissance du territoire (Aîné)

Objectifs et approches pédagogiques (Faisca)

Testons nos connaissances (Faisca)

10h-10h30 Les réalités des populations autochtones au pays

Portrait démographique et sanitaires des populations autochtones (faisca)

Populations urbaines et mobilité

10h30-1045 Pause

10h45 - 11h45 Le système colonial et la santé des populations autochtones (Carrie et Aîné)

Historique du système colonial au pays

Impact des mesures coloniales sur la santé des populations autochtones

Perceptions autochtones de la santé et zones de malentendus culturels

11h45-12h00 Sommaire et appréciation des participants

Prochaine séance

Deuxième demi-journée (19 et 20 décembre)

Formateurs : Sean Yaphe, Faisca Richer

9h-9h30 Retour sur la première séance

Questions commentaires suggestions

Objectifs et approches pédagogiques

9h30-10h30 Accès aux services pour les populations autochtones

Masures coloniales et discrimination systémique

Barrières à l'accès pour les populations autochtones au pays sean

10h30-1045 Pause 
10h45 - 11h45 La sécurité culturelle dans les soins et services de santé

Introduction au concept de sécurité culturelle

Les modèles de soins et services prometteurs sean

Changements requis à de multiples niveaux de gouvernance

\section{$11 \mathrm{~h} 45-12 \mathrm{~h} 00$ Sommaire et appréciation des participants}

Prochaine séance; vos histoires de cas SVP

\section{Module 2: Sécurité culturelle et Implications pour la pratique}

Ce deuxième module sera donné sous la forme d'un atelier d'échanges d'une demi journée, soit le 17 janvier pour le groupe 1 et le 23 janvier pour le groupe 2 .

Formateurs : Faisca Richer, Sean Yaphe

9h-9h30 Retour sur la dernière séance

Questions commentaires suggestions

Objectifs et approches pédagogiques

9h30-10h30 Nos 'angles morts' culturels

Comprendre les diverses formes de discrimination

L'impact de nos lunettes professionnelles

Le concept de sécurité culturelle dans mon champ pratique;

10h30-10h45 Pause

10h45-11h45 La sécurité culturelle au quotidien

Conseils pratiques et application dans mon milieu

La pratique réflective et l'humilité culturelle

\section{$11 \mathrm{~h} 45-12 \mathrm{~h} \quad$ Sommaire et appréciation des participants}

Post- test

Remerciements 


\section{Quelques lectures utiles}

Allan, B. \& Smylie, J. (2015). First Peoples, second class treatment: The role of racism in the health and well-being of Indigenous peoples in Canada. Toronto, ON: the Wellesley Institute. http://www.welleslevinstitute.com/wp-content/uploads/2015/02/Summary-First-Peoples-Second-ClassTreatment-Final.pdf

Health Working Group of the College of Family Physicians of Canada and Indigenous Physicians Association of Canada (2016) Health and Health Care Implications of Systemic Racism on Indigenous Peoples in Canada. http://www.cfpc.ca/uploadedFiles/Resources/_PDFs/SystemicRacism_ENG.pdf

Josée G. Lavoie Policy silences: why Canada needs a National First Nations, Inuit and Métis health policy Int J Circumpolar Health. 2013; $\quad 72: \quad$ 10.3402/ijch.v72i0.22690. https://www.ncbi.nlm.nih.gov/pmc/articles/PMC3875351/

State of the World's Indigenous Peoples (SOWIP). Indigenous Peoples' access to Health Services http://www.un.org/esa/socdev/unpfii/documents/2016/Docs-updates/The-State-of-The-WorldsIndigenous-Peoples-2-WEB.pdf

Statistiques Canada (2017) Les peuples autochtones au Canada : faits saillants du Recensement de 2016. http://www.statcan.gc.ca/daily-quotidien/171025/dq171025a-fra.pdf

Truth and Reconciliation Commission of Canada (2012). They came for the children. Historical document. http://www.myrobust.com/websites/trcinstitution/File/2039 T\&R eng web\%5B1\%5D.pdf 


\section{Appendix 2 : Pre-test questionnaire}

Les peuples autochtones au Canada

Ce petit questionnaire anonyme nous servira à mieux identifier vos besoins en lien avec cette formation; il vise essentiellement à évaluer votre niveau de connaissances de certains concepts de base, ainsi qu'à vérifier certaines croyances et attitudes en lien avec les soins offerts aux populations autochtones à Montréal.

Une version similaire de ce questionnaire vous sera également remise à la toute fin de la formation, afin de vous permettre de constater si la formation vous aura été utile. N'hésitez surtout pas à nous faire part de vos commentaires et suggestions sur tout aspect de la formation que vous souhaiteriez voir amélioré.

\section{Connaissance des peuples autochtones du Canada}

Veuillez indiquer si selon vous ces énoncés sont vrais ou faux.

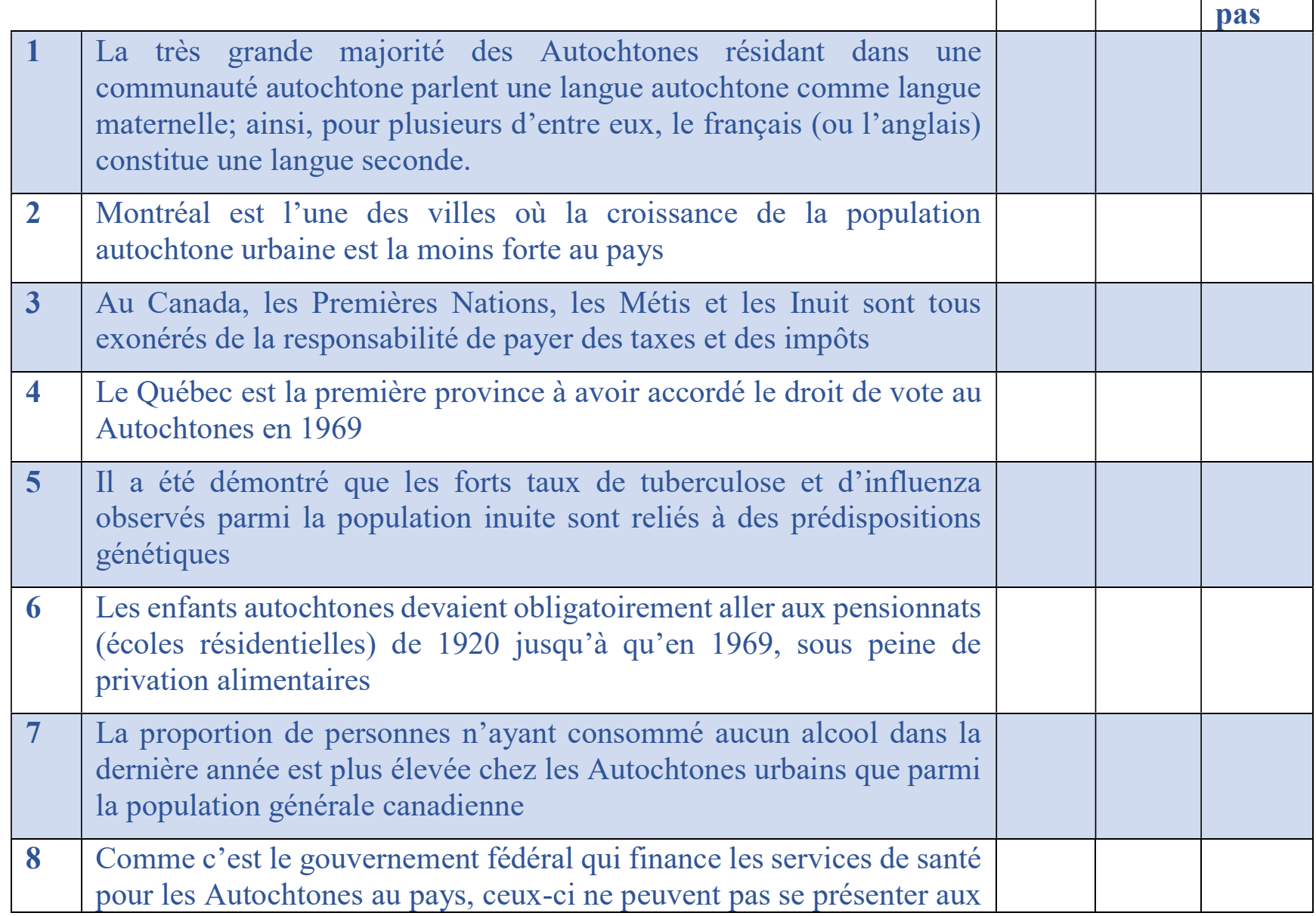




\begin{tabular}{|l|l|l|l|l|}
\hline & $\begin{array}{l}\text { cliniques au Québec sans avoir une référence du centre de santé de leur } \\
\text { communauté }\end{array}$ & & \\
\hline $\mathbf{9}$ & $\begin{array}{l}\text { Tous les Autochtones qui vivent à Montréal n'ont pas à débourser pour } \\
\text { obtenir leurs médicaments }\end{array}$ & $\begin{array}{l}\text { Selon le système de surveillance du VIH du Québec, moins de 1\% des } \\
\text { personnes séropositives sont d'origine autochtone }\end{array}$ & & \\
\hline $\mathbf{1 0}$ & & & \\
\hline
\end{tabular}

\section{Croyances et attitudes en lien avec les soins offerts aux populations autochtones à Montréal}

Dans quelle mesure êtes-vous en accord avec les énoncés suivants?

1 En tant que professionnel de la santé, j'ai surtout la responsabilité d'offrir des soins qui répondent aux standards de pratique habituels; il ne me revient pas de vérifier si les patients ont les ressources requises pour adhérer aux conseils que je leur prodigue

2

Les patients autochtones qui fréquentent les institutions de santé au Québec devraient pouvoir s'exprimer en français

3

Je suis conscient du fait que ma lunette culturelle de professionnel non-autochtone peut entraver la qualité de ma relation avec mes patients autochtones

$4 \quad$ Selon moi, les personnes d'origine autochtone devraient pouvoir bénéficier d'un statut et de privilèges uniques en tant que premiers habitants du pays

5 Je suis très à l'aise que mes patients autochtones utilisent à la fois des traitements conventionnels et la médecine traditionnelle

Les problèmes des Autochtones au Canada est le résultat de leurs difficultés à s'intégrer à la société occidentale

Je pense que les Autochtones au Canada font souvent l'objet de discrimination dans les institutions gouvernementales, incluant dans le système de services de santé 
Avez-vous déjà suivi une formation en lien avec la santé des Autochtones, et si oui, dans quel contexte?

Que signifie pour vous le concept de sécurité culturelle dans les services de santé? Vous sentez-vous en mesure de l'appliquer dans votre contexte de pratique au quotidien?

Que souhaiteriez-vous surtout apprendre au cours de cette formation?

Veuillez indiquer tout sujet ou thème que vous aimeriez voir abordés, toute habileté que vous souhaiteriez développer, ou encore toute question précise à laquelle vous aimeriez obtenir des réponses)

D’autres commentaires et suggestions en lien avec cette formation? N'hésitez pas!

\section{Merci!}




\section{Appendix 3: Session evaluation questionnaire}

Formation sur la sécurité culturelle des services de santé à Montréal

Le but de cette grille d'évaluation d'obtenir vos impressions sur l'atelier auquel que vous avez participé aujourd'hui. Celles-ci nous aiderons à améliorer notre formation.

Dans quelle mesure êtes-vous en accord avec les énoncés suivants?

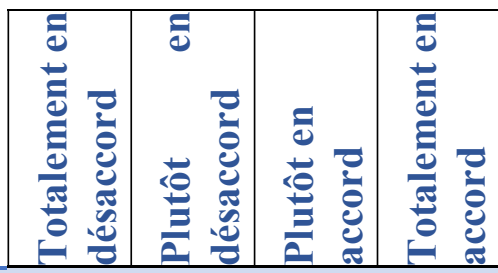

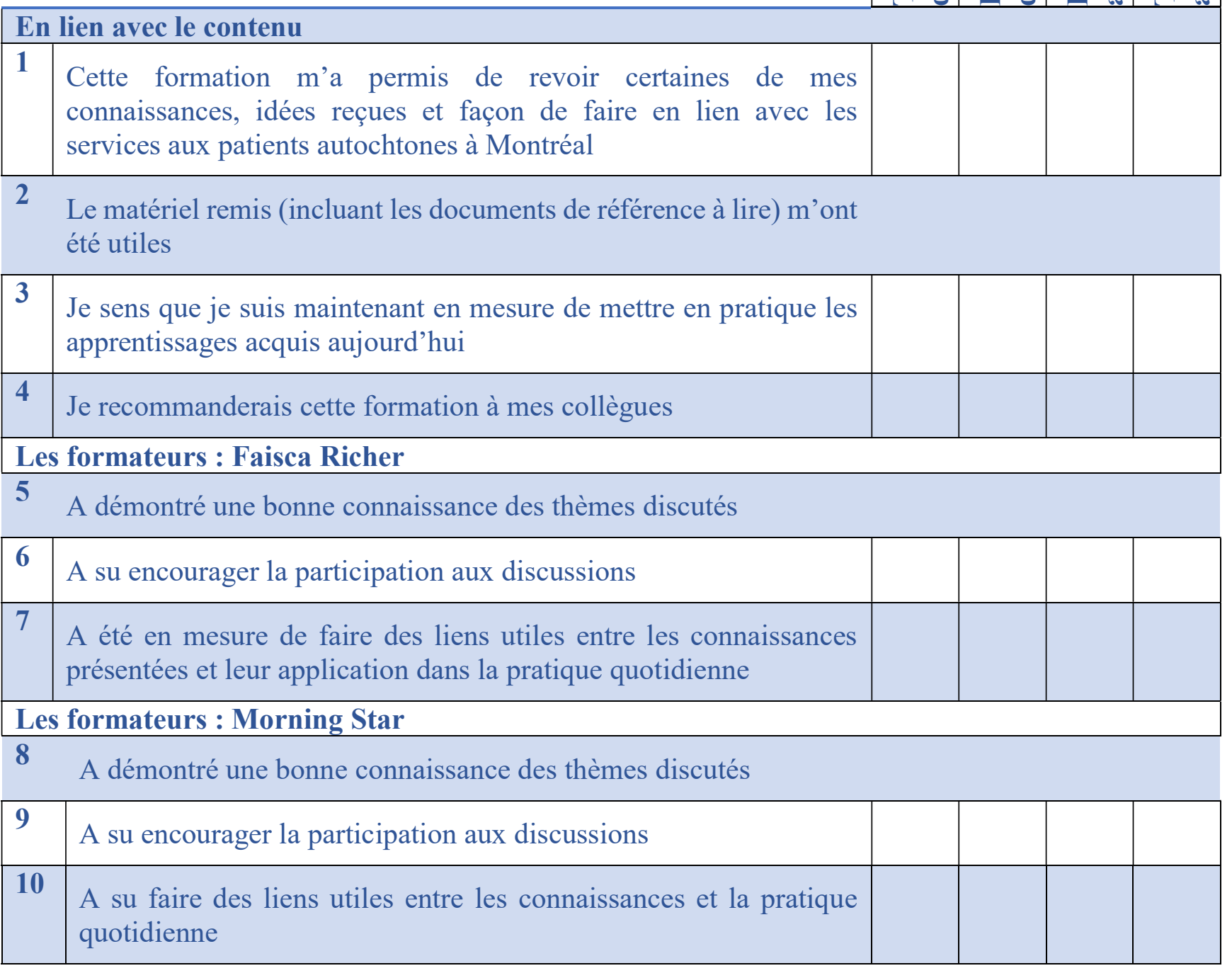


Quels sont, selon vous, les apprentissages les plus précieux que vous avez acquis aujourd'hui?

Comment pourrions-nous améliorer cette formation, selon vous?

D’autres commentaires et suggestions en lien avec cette formation? N'hésitez pas!

Merci! 